\title{
Barriers to participation in HIV vaccine trials and cancer trials: a cost-gain analysis
}

\author{
S Dhalla ${ }^{1 *}$, G Poole ${ }^{2}$ \\ From AIDS Vaccine 2012 \\ Boston, MA, USA. 9-12 September 2012
}

\section{Background}

Previous studies examining barriers and willingness to participate in HIV vaccine trials have demonstrated the role of factors identified by the Health Belief Model. Barriers to cancer trials can also be understood in terms of a theoretical framework consisting of the locus of the barrier (personal vs. social) and the nature of the barrier (risk vs. cost). In this systematic review of review articles, we extend this framework to another life-threatening disease, cancer. The purpose is to improve conceptual clarity about volunteering in clinical trials by comparing and contrasting barriers in these two areas.

\section{Methods}

In 2012, two people independently searched the Cochrane Database for Systematic Reviews, Pubmed, Embase, and Google Scholar to identify review articles examining cancer trial barriers to participation. Search terms used were: "cancer", "oncology", "cancer trials", "oncology trials", "clinical trials", "medical research", "willingness to participate", "barriers". Review articles were also retrieved from our search examining motivators to participation in cancer research and from bibliographic references.

\section{Results}

We retrieved 19 review articles from 2000-2012 examining barriers to participation in cancer trials. "Reduced quality of life" / "distrust of institutions" / "loss of control" were personal risks (PR). "Perceptions of the provider" / "subjective norms" were social risks (SR). "Side effects" / "experimental nature of the trial" were personal costs (PC). Misconceptions included "confidentiality concerns". Consistent with HIV vaccine trials, most barriers with regards to cancer trials were related to PR and PC. More

${ }^{1}$ University of British Columbia, Vancouver, Canada

Full list of author information is available at the end of the article misconceptions were identified in HIV vaccine preparedness studies (VPS).

\section{Conclusion}

Personal risk, PC, and SR barriers were similar to those identified in HIV VPS, but more misconceptions were identified in the latter. Understanding barriers can result in better recommendations on how to overcome these barriers. A limitation is that cancer populations are different than those affected by HIV.

\section{Author details}

${ }^{1}$ University of British Columbia, Vancouver, Canada. ${ }^{2}$ School of Population and Public Health, University of British Columbia, Vancouver, Canada.

Published: 13 September 2012

doi:10.1186/1742-4690-9-S2-P109

Cite this article as: Dhalla and Poole: Barriers to participation in HIV vaccine trials and cancer trials: a cost-gain analysis. Retrovirology 2012 9(Suppl 2):P109.
Submit your next manuscript to BioMed Central and take full advantage of:

- Convenient online submission

- Thorough peer review

- No space constraints or color figure charges

- Immediate publication on acceptance

- Inclusion in PubMed, CAS, Scopus and Google Scholar

- Research which is freely available for redistribution

\section{Biomed Central}

๑ 2012 Dhalla and Poole; licensee BioMed Central Ltd. This is an Open Access article distributed under the terms of the Creative Commons Attribution License (http://creativecommons.org/licenses/by/2.0), which permits unrestricted use, distribution, and reproduction in any medium, provided the original work is properly cited. 